Supplement of Geosci. Model Dev., 12, 3439-3447, 2019

https://doi.org/10.5194/gmd-12-3439-2019-supplement

(C) Author(s) 2019. This work is distributed under

the Creative Commons Attribution 4.0 License.

(c) (1)

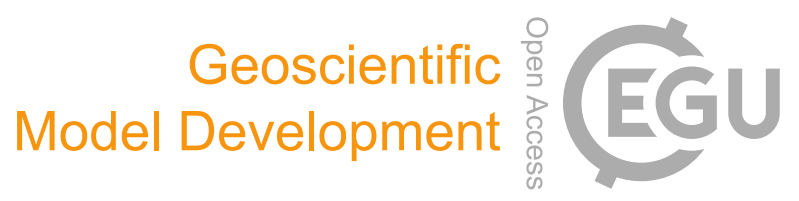

Supplement of

\title{
Revised treatment of wet scavenging processes dramatically improves GEOS-Chem 12.0.0 simulations of surface nitric acid, nitrate, and ammonium over the United States
}

Gan Luo et al.

Correspondence to: Gan Luo (gluo@ albany.edu)

The copyright of individual parts of the supplement might differ from the CC BY 4.0 License. 


\section{Supplementary information}

Table S1. Observed annual mean surface concentration of sulfate at IMPROVE and CSN sites. Annual mean surface concentrations (Mean), normalized mean bias (NMB), and correlation coefficient $(r)$ between observed and simulated annual mean sulfate by GC12, Knew, $\mathrm{ICCW}_{\mathrm{t}}$, and $\mathrm{ICCW}_{\mathrm{t}} \mathrm{EW}$ cases.

\begin{tabular}{cccc}
\hline & SO4 & \\
\hline & $\begin{array}{c}\text { Mean } \\
\left(\mu \mathrm{g} \mathrm{m}^{-3}\right)\end{array}$ & $\begin{array}{c}\text { NMB } \\
(\%)\end{array}$ & $r$ \\
\hline Observation & 1.30 & & \\
\hline GC12 & 1.56 & 19.6 & 0.92 \\
Knew & 1.59 & 22.6 & 0.92 \\
ICCW $_{\mathrm{t}}$ & 1.37 & 5.0 & 0.93 \\
ICCW $_{\mathrm{t}}$ EW & 1.18 & -9.3 & 0.92 \\
\hline
\end{tabular}

(a) SO4 at IMPROVE $+\mathrm{CSN}, \mathrm{N}_{\mathrm{obs}}=214$

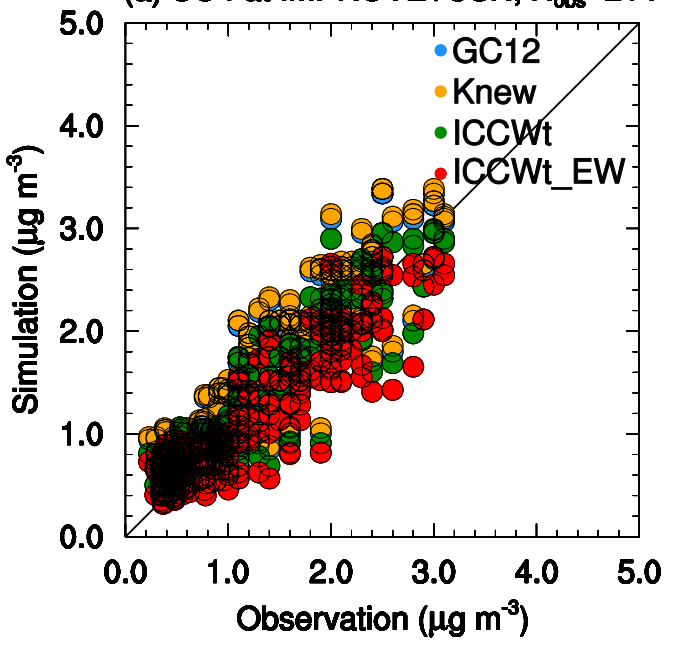

(b) Monthly mean SO4 at IMPROVE+CSN

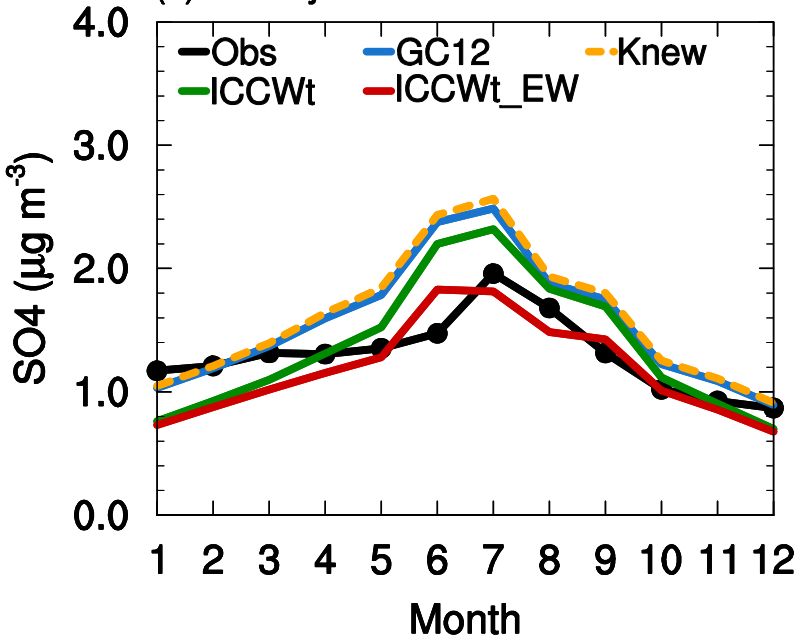

Figure S1. (a) Scatter plot of observed and simulated annual mean sulfate at IMPROVE and CSN sites and (b) variations of monthly mean for year 2011 showing the comparison between sulfate mass concentrations observed at IMPROVE and CSN sites (black) and simulated by GC12 (blue), Knew (yellow dash), ICCW cases. 